\title{
A programmed labour protocol for optimizing labour and delivery
}

\section{Kumud Gupta*, Smarika Dubey, Shital Bhardwaj, Meenal Parmar}

Department of Obstetrics \& Gynaecology, NIMS Medical Collage and Hospital, Jaipur, Rajasthan, India

Received: 14 February 2015

Revised: 24 February 2015

Accepted: 01 March 2015

\author{
*Correspondence: \\ Dr. Kumud Gupta, \\ E-mail: ashokgupta07@gmail.com
}

Copyright: ( $\odot$ the author(s), publisher and licensee Medip Academy. This is an open-access article distributed under the terms of the Creative Commons Attribution Non-Commercial License, which permits unrestricted non-commercial use, distribution, and reproduction in any medium, provided the original work is properly cited.

\begin{abstract}
Background: Objectives: 1) To evaluate the effect of programmed labor on duration of labor 2) To assess efficiency of analgesics in reducing severity of labor pains and 3) To find out any maternal and fetal/neonatal complications.

Methods: 100 primigravida pregnant women meeting inclusion criteria admitted in labor room 50 were randomly enrolled in study group and 50 in control group.

Results: Significant reduction in duration of active phase of labor and $43(86 \%)$ cases had pain relief. Out of them 20 $(40 \%)$ cases experienced excellent pain relief while in controls, only $22 \%$ had pain relief.

Conclusions: Labour analgesia ensures pain relief, avoid maternal hyperventilation controls alteration of placental circulation thereby safe guarding the fetus against hypoxia. Thus programmed labor is easy, simple and effective method for painless delivery
\end{abstract}

Keywords: Programmed labour, Analgesia, Pain relief

\section{INTRODUCTION}

Labour is defined as the progressive dilatation of uterine cervix with co-ordinate uterine contractions that effect in and expulsion of the products of conception. These uterine contractions are perceived as labor pains. Labour is physiological but painful event. The anxiety, fear and stress a women suffers is beyond description. Labour analgesia ensures pain relief, controls alteration of placental circulation thereby safe guarding the fetus against hypoxia.

Programmed labor concept: This concept rest on three pillars;

1. Providing optimum pain relief - Use of analgesics and antispasmodics.

2. Ensuring adequate uterine contractions - Active management of labor
3. Close clinical monitoring of labor events Maintaining a PARTOGRAM

Currently, the proven obstetric analgesia is epidural anesthesia. ${ }^{1}$ In places where epidural analgesia cannot be provided, tramadol, a centrally acting non opioid analgesic has been used as a labor analgesic. ${ }^{2}$ Ketamine, a dissociative anesthetic, is gaining popularity as it provides excellent pain relief and patient satisfaction. ${ }^{3}$ The present study attempts to compare the duration of labor and maternal outcome in programmed labor protocol and conventional labor protocol followed in our hospital.

\section{Aims and objectives}

1) To evaluate the effect of programmed labor on duration of labor.

2) To assess efficiency of analgesics in reducing severity of labor pains. 
3) To find out any maternal and fetal/neonatal complications

\section{METHODS}

The present prospective randomized study was undertaken at national institute of medical sciences Jaipur (India). It was approved by ethical committee of the institute.

The patients in active labor were divided into two groups by simple randomization.

Group I: 50 (cases) for programmed labor.

Group II: 50 (controls) for traditional management of labour.

Total sample size was 100 primigravidas.

On admission to Labor room detailed history was takes a thorough physical and general examination was done. Obstetrical examination including per vaginal examination was done and pelvic assessment was done to rule out cephalopelvic disproportion, after confirmation subject in active labor ARM was done for confirmation of colour of liquor, cases were selected for study. All subjects were subjected for routine investigation.

Every women were counseled regarding drugs used in programmed labor and after counseling written informed consent was taken.

Level of analgesia assessed using following scale:

0 - No pain relief

1 - Mild pain relief

2 - Moderate pain relief

3 - Excellent pain relief

\section{Inclusion criteria}

1. Age, between 21-35 years.

2. No identifiable medical or obstetric complications present.

3. Primigravida with singleton pregnancy with cephalic presentation with spontaneous onset of labor.

4. Gestational maturity of 37-41 week.

5. Admission NST-reactive.

6. Active phase of labor with cervical dilatation $4 \mathrm{cms}$ and $50 \%$ effaced.
7. Liquor should be clear after ARM.

8. No clinical evidence of cephalopelvic disproportion.

\section{Exclusion criteria}

1. High risk cases like antepartum haemorrhage, preeclampsia, diabetes complicating pregnancy, polyhydramnios, oligohydramnios, cephalopelvic disproportion, malpresentation, and pre labor rupture of membranes.

2. Patient who are not willing to sign informed consent will be excluded from the study.

\section{Protocol}

$>$ The cervix should be 3.0-4.0 cm dilated, $>50 \%$ effaced and head is at 0 or -1 station

Amniotomy is performed at 3-4 cm dilatation.

> Start an intravenous infusion line with 5\% Ringer Lactate solution@ about 20 drops/min

Ensure that pains are optimal that is $3-4 \mathrm{c} / 35$ $45 \% / 10$ '.

$>$ If needed half an hour after amniotomy, Oxytocin drip 5units in 500ml RL started at 8-10drops / min and titrated every $30 \mathrm{mins}$ up to adequate contractions (3-4 c/ 35-45"/10') achieved.

> Inj. tramadol $1 \mathrm{mg} / \mathrm{kg}$ and inj. drotaverine hydrochloride $40 \mathrm{mg}$ I.M. single dose is given at amniotomy.

$2 \mathrm{mg}$ of diazepam $+6 \mathrm{mg}$ pentazocine given i.v. at amniotomy and repeated 2 hourly on patient demand.

Progress of labour monitored by partogram and $\mathrm{p} / \mathrm{v}$ examination done every 2 hourly after amniotomy.

$>10$ units of oxytocin diluted in $20 \mathrm{ml}$ of saline and given through the umbilical vein of the placenta or administer it slow intravenous to the mother.

Or

Inj. prostadin $125 \mathrm{mcg}$ given IM after birth of the baby.

$>$ Duration of active phase of labor, $2^{\text {nd }}$ stage and $3^{\text {rd }}$ stage of labor will be assessed.

Neonatal assessment is done with APGAR score at $1 \mathrm{~min}$ and $5 \mathrm{~min}$. 
$>$ Maternal pain relief will be assessed with the help of visual analogue scale in the immediate postnatal period.

\section{Control group}

Partographic monitoring of labor was done.

Inj. tramadol $50 \mathrm{mg}$ IM was used for pain relief.

Diazepam, pentazocine and drotaverine were not used.

\section{Assessment}

1. Duration of labor.

2. Pain relief during labor.

3. APGAR score at 1 minute and at 5 minutes

4. Perinatal morbidity and mortality.

5. Side effect to the mother and child.

\section{RESULTS}

1) The rate of cervical dilatation was $1.72 \mathrm{~cm} / \mathrm{hour}$ in cases and $1.23 \mathrm{~cm} /$ hour in controls $(\mathrm{P}<0.0001)$ which is significant.

2) The duration of active phase of labor was significantly reduced $(3.45$ hours in cases \& 4.78 hours in controls, which is statistically significant $\mathrm{P}$ $<0.0001$ ).

3) The duration of II stage of labor was $27.4 \mathrm{~min}$ in cases \& 34.0 min in controls ( $\mathrm{P}<0.0004)$.

4) Majority of the patients in both groups delivered vaginally (90\% in study group \& $92 \%$ in controls).

5) $86 \%$ patients in study group had pain relief as compared to $22 \%$ in control group. It is statistically significant.

6) The cases had significantly more drug related side effects like nausea, vomiting, drowsiness, that subsided after 12 hours .

7) There were no significant fetal/neonatal complications in either group.

Table 1: Age distribution of subject in both groups.

\begin{tabular}{|lll|}
\hline $\begin{array}{l}\text { Age } \\
\text { (years) }\end{array}$ & $\begin{array}{l}\text { Cases } \\
(\mathrm{n}=50)\end{array}$ & $\begin{array}{l}\text { Control } \\
(\mathrm{n}=50)\end{array}$ \\
\hline$<20$ & 13 & 9 \\
\hline $21-25$ & 31 & 34 \\
\hline $26-30$ & 6 & 7 \\
\hline$>30$ & 0 & 0 \\
\hline
\end{tabular}

Maximum subjects in both groups were $<25$ years
Table 2: Rate of cervical dilatation in active phase.

\begin{tabular}{|ll|}
\hline Rate of cervical dilatation \\
\hline Cases & $1.72 \mathrm{~cm} /$ hour \\
\hline Controls & $1.23 \mathrm{~cm} /$ hour \\
\hline
\end{tabular}

Cervical dilatation was significantly faster in cases $(\mathrm{P}<0.0001)$

Table 3: Duration of stages of labour.

\begin{tabular}{|llll|}
\hline & Active phase & II stage & III stage \\
\hline Case & 3.45 hours & $27.4 \mathrm{~min}$ & $4.46 \mathrm{~min}$ \\
\hline Control & 4.78 hours & $34.0 \mathrm{~min}$ & $4.45 \mathrm{~min}$ \\
\hline
\end{tabular}

There was statistically significant difference in the duration of II stage of labor

Table 4: Pain relief score.

\begin{tabular}{|lllll|}
\hline Score & Cases & Percentage & Control & Percentage \\
\hline 3 & 1 & $02 \%$ & 0 & 0 \\
\hline 2 & 19 & $38 \%$ & 0 & 0 \\
\hline 1 & 23 & $46 \%$ & 11 & $22 \%$ \\
\hline 0 & 7 & $14 \%$ & 39 & $78 \%$ \\
\hline
\end{tabular}

Pain relief was much better in study group as compared to controls

Table 5: Complication in both group.

\begin{tabular}{|lll|}
\hline Complication & Cases & Control \\
\hline Nausea & 3 & 2 \\
\hline Vomiting & 3 & 1 \\
\hline Drowsiness & 2 & 0 \\
\hline Tachycardia & 2 & 2 \\
\hline Hypertonic contractions & 1 & 1 \\
\hline Cervical/vaginal tears & 3 & 2 \\
\hline Rupture uterus & 0 & 0 \\
\hline
\end{tabular}

Side effects observed more in cases than in controls which are related to drugs

Table 6: APGAR score.

\begin{tabular}{|lll|}
\hline A PGAR score & Cases & Controls \\
\hline At $1 \min (4-5)$ & 4 & 5 \\
\hline At $1 \min (6-7)$ & 46 & 45 \\
\hline At $5 \min (6-7)$ & 3 & 5 \\
\hline At $5 \min (8-9)$ & 47 & 45 \\
\hline
\end{tabular}

APGAR score was comparable in both groups

\section{DISCUSSION}

Programmed labor protocol was designed for shorter, safer and relatively painless vaginal delivery, making it a joyful and satisfactory event. 


\section{Cervical dilatation}

The cervix dilated at a faster rate $(1.72 \mathrm{~cm} / \mathrm{hour})$ in programmed labor than in controls $(1.23 \mathrm{~cm} /$ hour $)$. It resulted in shorter labours.

According to Mishra et al. ${ }^{4}$ and Singh et al., ${ }^{5}$ it is the effect of drotaverine. Veronica et al. ${ }^{6}$ noticed that rate of cervical dilatation was nearly double $(2.3 \mathrm{~cm} /$ hour $)$ in subjects and $(1.2 \mathrm{~cm} /$ hour $)$ in controls.

\section{Duration of labour}

In our study, mean duration of active phase of labor in primi was 3.45 hours (cases) and 4.78 hours (controls). It was statistically significant $(\mathrm{P}<0.0001)$.

Mean duration of II stage of labor was 27.4 minutes (cases) and 34 minutes (controls) which was statistically significant $(\mathrm{P}<0.0004)$.

Dr. Chauhan et al. ${ }^{7}$ found duration of first stage of labor to be 3.4 hours. Dr. Daftary et al. ${ }^{8}$ reported active phase duration to be 3.5 hours in cases and that of II stage of labor to be 26 minutes.

\section{Pain relief}

Pain relief plays a vital role in maternal well-being. Pain and fear retard the progress of labor. It prevents maternal hyperventilation, undue muscular efforts and exhaustion. Hence, pain relief was one of the important objectives of the study.

We observed that $43(86 \%)$ cases had pain relief. Out of them $20(40 \%)$ cases experienced excellent pain relief while in controls, only $22 \%$ had pain relief.

Meena Jyoti et al. ${ }^{9}$ noticed that $54 \%$ achieved good and $32 \%$ achieved moderate pain relief. Veronica et al. ${ }^{6}$ reported total pain relief in $70 \%$ cases.

\section{Maternal outcome}

None of the patients had any major complications of labour.

In programmed labor group, drug related side effects like nausea, vomiting, drowsiness, tachycardia were seen. All the side effects subsided by 12 hours after delivery.

One cases developed hypertonic uterine contractions.

Veronica et al. ${ }^{5}$ had similar findings. Tachycardia (80\%) was the commonest side effect followed by nausea and vomiting (10\%).

\section{Neonatal outcome}

APGAR score of babies in both groups were good ( $>7$ in $94 \%$ cases \& in $90 \%$ controls).

\section{CONCLUSION}

"Programmed labour protocol" provide effective analgesia and side effects of drugs which were observed are minimal, and safe for the fetus. Labour is cherished with pleasure and childbirth becomes a joyous event for the mother.

\section{Funding: No funding sources}

Conflict of interest: None declared

Ethical approval: The study was approved by the institutional ethics committee

\section{REFERENCES}

1. Spong CY, Cunningham FG, Leveno KJ, Bloom SL, Hauth J, Rouse D. Obstetric analgesia. In: Spong CY, Cunningham FG, Leveno KJ, Bloom SL, Hauth J, Rouse D, eds. Williams-Obstetrics. 23rd ed. New York: McGraw-Hill; 2010: 454.

2. Raffin RB, Friderichs E., Reiman W. Obstetric analgesics and anesthetics. J Pharmacol Experiment Therapeut. 1992;260:275-85.

3. American College of Obstetricians and Gynecologists. Obstetric analgesia and anesthesia. In: ACOG, eds. Practice Bulletin No. b36. USA: ACOG; July 2002.

4. Mishra SL, Toshniwal A. Effect of drotaverine HCL on cervical dilatation in labour, a comparison with valethamate bromide. $\mathbf{J}$ Obstet Gynecol India. 2002;52:76.

5. Singh KC, Jain P, Goel N. Drotaverine hydrochloride for augmentation of labour. Int $\mathbf{J}$ Gynaecol Obstet. 2004;84:17-22.

6. Irene V, Kaur V. Programmed labor for optimizing labor \& delivery. JK Sci. 2008;10:62-4.

7. Chauhan R, Gupta AA. A clinical study of programmed labor \& its outcome. J Obstet Gynecol Fam Welfare. 2003;5:8-9.

8. Daftary SN, Desai SV, Thanawala U, Bhide A, Levi J, Patki A, et al. Programmed labuor - indigenous protocol to optimize labor outcome. South Asian Feder Obstet Gynecol. 2009;1:61-4.

9. Jyoti M, Singhal P, Choudhary D. Programmed labour. J Obstet Gynecol India. 2006;56:53-5.

DOI: $10.5455 / 2320-1770.1 j r \operatorname{cog} 20150434$ Cite this article as: Gupta K, Dubey S, Bhardwaj S, Parmar M. A programmed labour protocol for optimizing labour and delivery. Int J Reprod Contracept Obstet Gynecol 2015;4:457-60. 